\section{AFRC lays down the law}

\section{London}

BRITISH university departments and laboratories run by the Agricultural and Food Research Council (AFRC) are being sent copies of the AFRC's new guidelines on the use of animals in research. This is the first time that one of the research councils has released its own document to ensure that animal researchers are fully aware of their responsibilities under the law. AFRC funding will in future be conditional on researchers having read and complied with the new guidelines.

The guidelines themselves are uncontentious, merely summarizing Home Office requirements to comply with UK animal experimentation legislation, and the separate agriculture ministry rules for the use of farm animals in research. But animal welfare groups say their release is significant, marking a new realization among British research funding agencies that ensuring animal welfare should not simply be left to government inspectors responsible for policing the law.

Michael Balls, director of the Fund for the Replacement of Animals in Medical Experiments, believes the AFRC's move is, in part, a response to the infamous 1990 'Feldberg case', where the Scottish animal welfare group Advocates for Animals exposed serious breaches of the 1986 Animals (Experimental Procedures) Act by Wilhelm Feldberg, a researcher at the Medical Research Council's (MRC) National Institute for Medical Research in London.

Mari Williams, secretary to the AFRC working party that drew up the new guidelines, says that the AFRC group was intending to set up an animal research working group before the Feldberg revelations surfaced, but admits that the incident "focused minds". The MRC itself has not issued a similar document, but did set up a new secretariat to monitor animal research in the wake of the Feldberg allegations.

Meanwhile, a second Advocates for Animals investigation has been generating considerable heat. In November, the group released the first instalment of a three-part report detailing primate research papers which, it was alleged, should not have been approved under the 1986 Act (see Nature 354, 177; 21 November 1991). The MRC, which funded more than half of the projects involved, has since published its own internal inquiry into the allegations, concluding that in each case the work was directly relevant to to human medical disorders and that the results could not have been achieved without the use of animals.

But the Advocates for Animals report now seems to have been picked up by the extremist wing of the British animal rights

\section{LONDON ZOO}

movement. Shortly before Christmas, The Scotsman newspaper received a letter from the militant Animal Liberation Front (ALF), claiming responsibility for a recent spate of firebomb attacks against Scottish research laboratories and meat-handling depots, and threatening to destroy the primate unit at the MRC's Reproductive

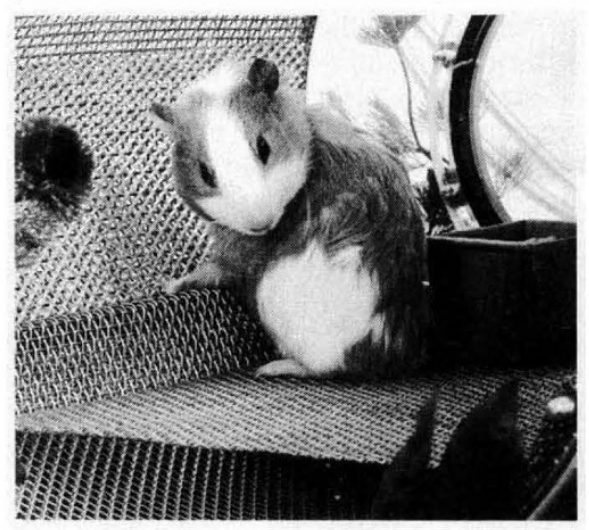

Biology Unit in Edinburgh, if it is not closed within 16 weeks. Three of the 13 papers detailed in the first part of the Advocates for Animals report were by researchers at the Edinburgh unit, looking at reproductive behaviour or the secretion of reproductive hormones, and involved either surgery or aggression-induced stress.

Advocates for Animals and the MRC have since released a joint statement condemning the ALF threat, and Advocates for Animals director Les Ward says that he is now looking again at how best to present the remaining two parts of his group's primate research investigation, due to be published later this month. The first part of the report named the researchers and laboratories involved in the work. Ward says he is considering omitting this information from the rest of the report, although he thinks that the ALF threat is probably a hoax, as he doubts if the group would attempt to destroy a laboratory that is still housing animals.

Peter Aldhous

\title{
Rebel fellows claim success
}

\section{London}

DisGRUNTLED fellows of the Zoological Society of London (ZSL) who have been seeking to replace the management team responsibile for running the society's showcase, London Zoo, claimed a major victory on Monday this week after a meeting called to debate the ZSL's attempts to address the financial crisis that has threatened the zoo with closure. The meeting was called by the Ad Hoc Group of ZSL Fellows, to debate a motion of no confidence in the ZSL's governing council, and to secure changes in the zoo's management (see Nature 354, 261; 28 November 1991).

Although the council was saved the indignity of being forced to resign, Graham Mitchell, from the medical school at Guy's Hospital, London, and a member of the $A d$ Hoc Group, believes the group's action has forced the council to rethink its approach - and that there is now cause for optimism about the zoo's future. He argues that the council has now rejected the zoo management's "grandiose" plans to redevelop the zoo's Regent's Park site into a centre featuring large 'themed' exhibits featuring the ZSL's work in conservation. In their place, says Mitchell, the plan now given the council's backing includes many of the features of the Ad Hoc Group's own low-budget proposal, which featured captive breeding programmes and relied on the re-use of existing buildings, rather than expensive redevelopment.

The sequence of votes taken at the meeting yields a confusing picture: fellows declared their lack of confidence in the council's past performance by 208 votes to 56 ; but the council gained the backing of the same gathering to continue in its attempts to save the zoo by 141 votes to 96 (with an increased number of abstentions). But Mitchell points out that the second vote came after the presentation of the council's new redevelopment plan, costed at around $£ 9$ million $-£ 7$ million less than the least expensive figure quoted before Christmas, and a fraction of a mammoth $£ 60$ million proposal touted by a specially created private company, Regent's Park Zoo Limited.

After the council's treasurer, Peter Holwell, assured fellows that the zoo's management would also be overhauled (the AdHoc group has been highly critical of the zoo management, which it regards as ineffective and 'top heavy'), the rebel fellows pulled back from their threat to remove the council, with the request for the council to resign being defeated by an overhelming margin.

Despite the renewed optimism among the council's critics, there is now very little time in which to assemble financial backing to secure the zoo's future, with closure threatened sometime later this year if no firm offers materialize. Mitchell says that the council must act on its promise to reform the zoo's management something that may place the jobs of some senior staff in jeopardy - if further challenges from the fellowship are to be prevented.

Peter Aldhous 